Supporting Information

of

\title{
A Versatile Carbon Monoxide Nanogenerator for Enhanced Tumor Therapy and Anti-Inflammation
}

Shi-Bo Wang, ${ }^{\dagger},, \#$ Cheng Zhang, $,{ }^{\dagger}, \#$ Zhao-Xia Chen,${ }^{\dagger}$ Jing-Jie Ye, ${ }^{\dagger}$ Si-Yuan Peng, ${ }^{\dagger}$ Lei Rong, ${ }^{\dagger}$ Chuan-Jun Liu, ${ }^{\dagger}$ and Xian-Zheng Zhang ${ }^{\dagger, * * *}$

$\dagger$ Key Laboratory of Biomedical Polymers of Ministry of Education \& Department of Chemistry, Wuhan University, Wuhan 430072, P. R. China

† Institute for Advanced Studies (IAS), Wuhan University, Wuhan 430072, P. R. China

* Corresponding author. E-mail address: xz-zhang@whu.edu.cn

\# These authors contributed equally to this work. 


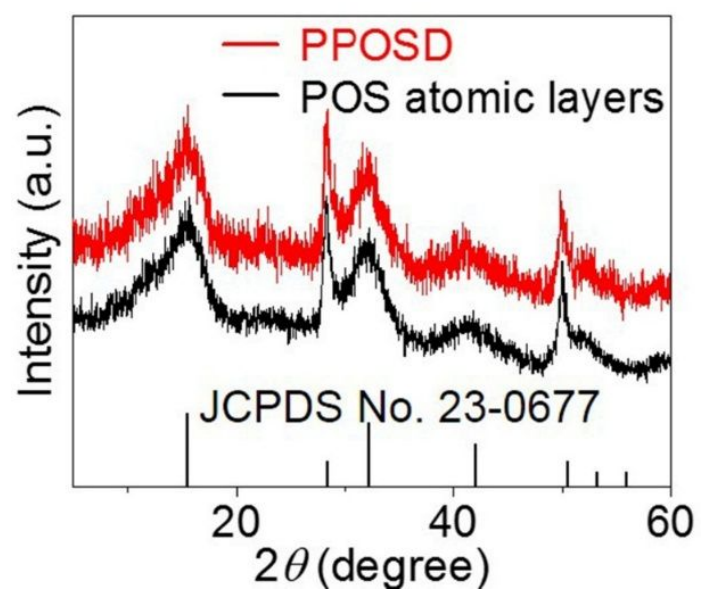

Figure S1. PXRD patterns of PPOSD and POS atomic layers. 


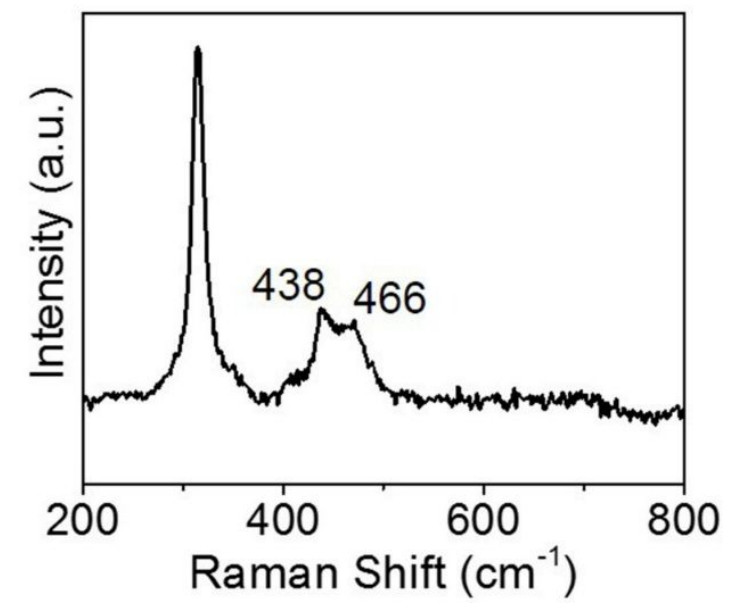

Figure S2. Raman spectrum for POS atomic layers. The peaks at 438 and $466 \mathrm{~cm}^{-1}$ demonstrated the presence of $\mathrm{SnO}_{2}$ phase in POS atomic layers. 


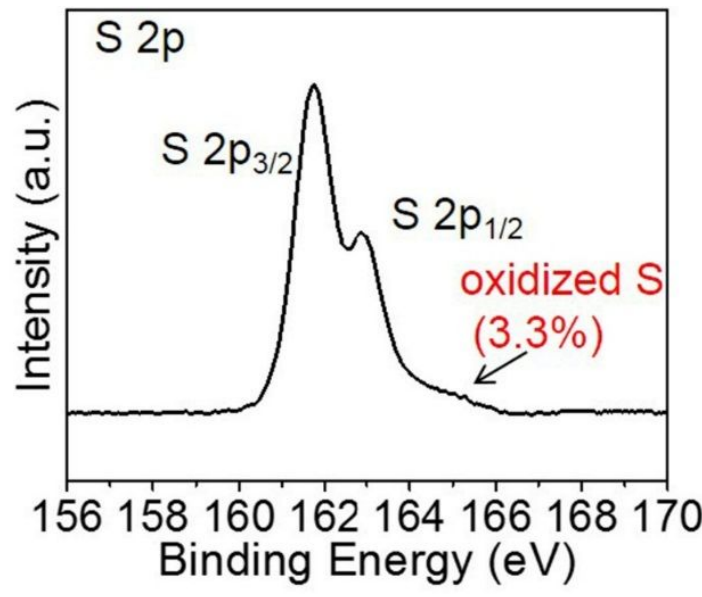

Figure S3. S 2p XPS spectrum for POS atomic layers. The oxidized S was detected to be $3.3 \%$. 


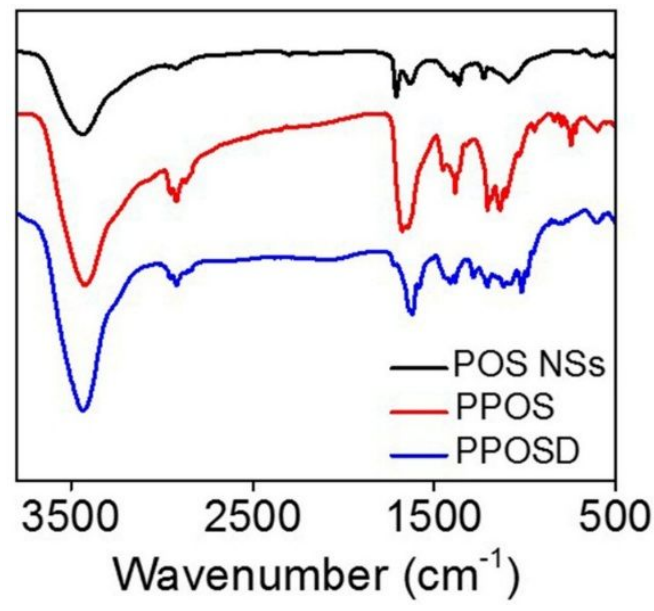

Figure S4. FTIR spectra of POS NSs, PPOS, and PPOSD. 


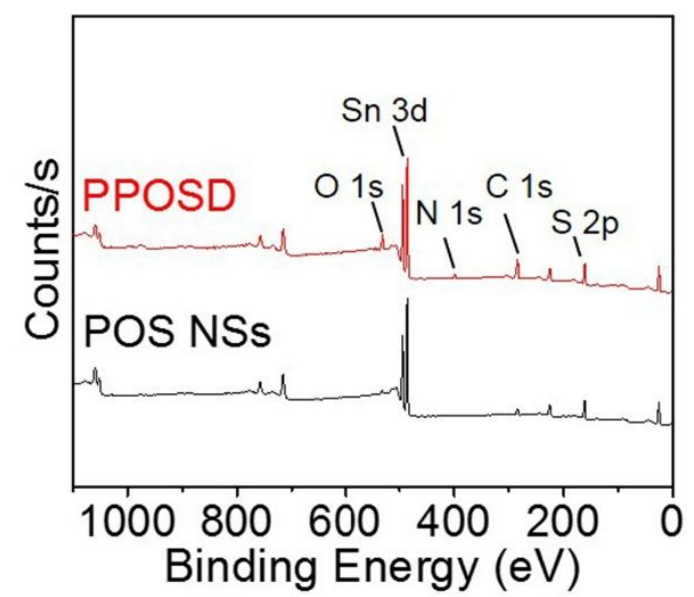

Figure S5. XPS spectra of PPOSD and POS NSs. 


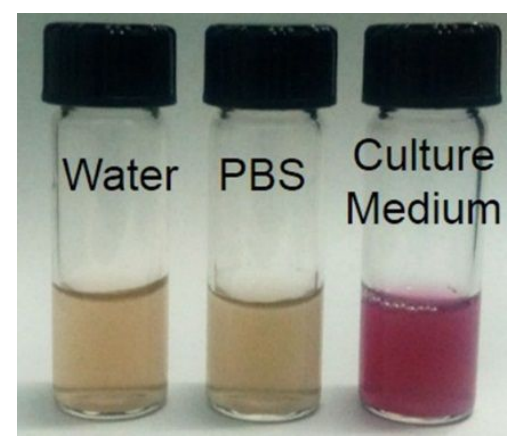

Figure S6. Digital photographs of PPOSD $(50 \mu \mathrm{g} / \mathrm{mL})$ in water, PBS and culture medium (DMEM). 


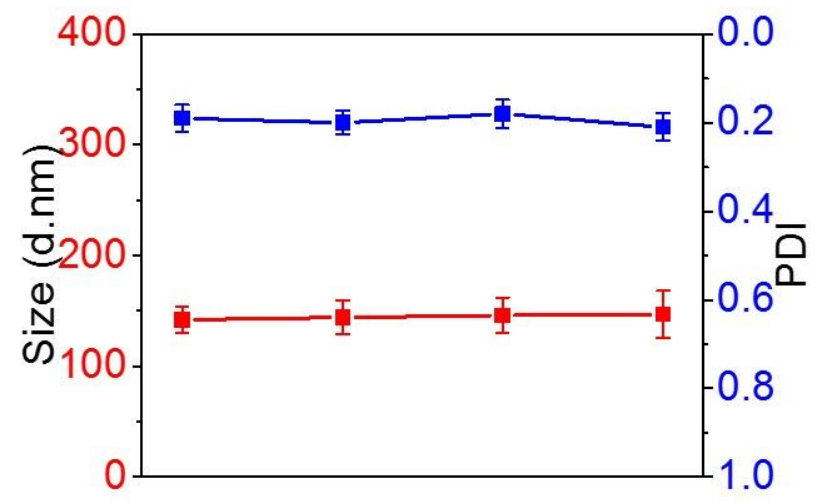

Figure S7. The hydrodynamic size distribution and PDI changes of PPOSD in DI water during 7 days. 


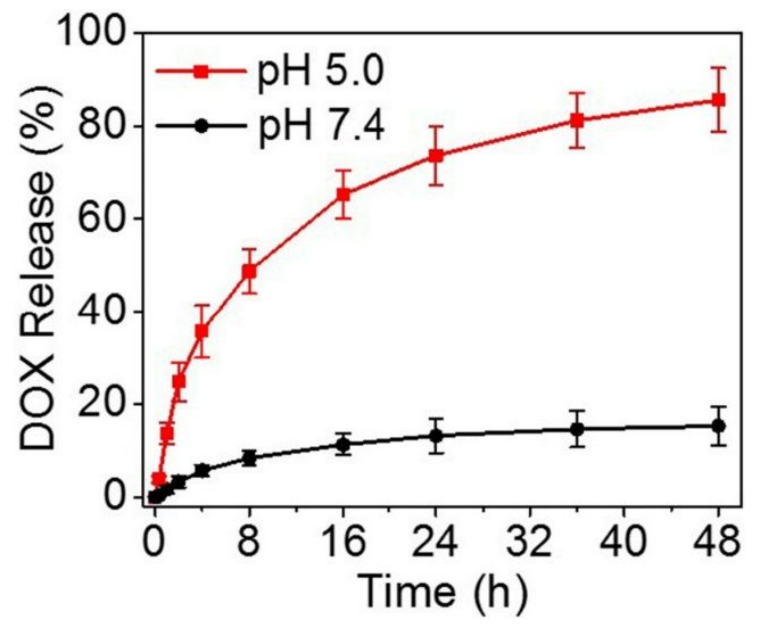

Figure S8. Drug release behavior of PPOSD in $\mathrm{pH} 5.0$ and 7.4 PBS solution. 


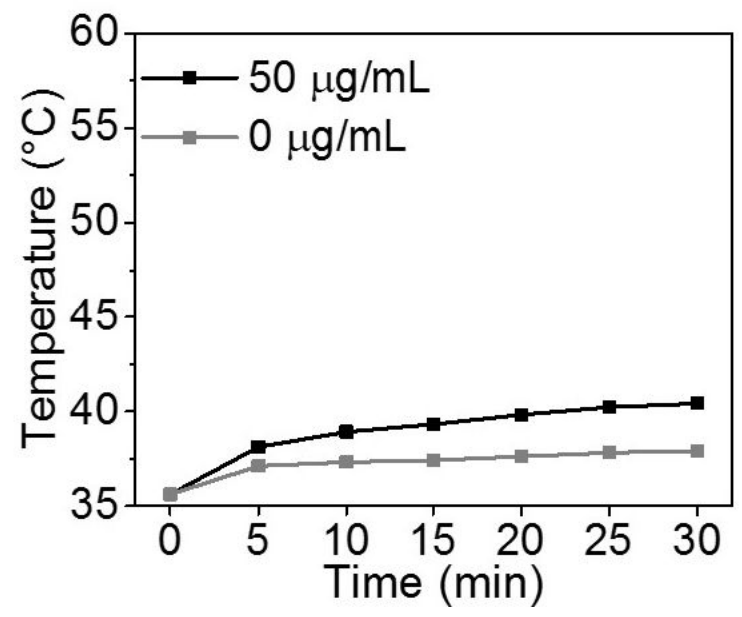

Figure S9. Temperature changes of PPOSD solution ( 0 and $50 \mu \mathrm{g} / \mathrm{mL})$ during $561 \mathrm{~nm}$ laser irradiation $\left(0.5 \mathrm{~W} / \mathrm{cm}^{2}\right)$. 

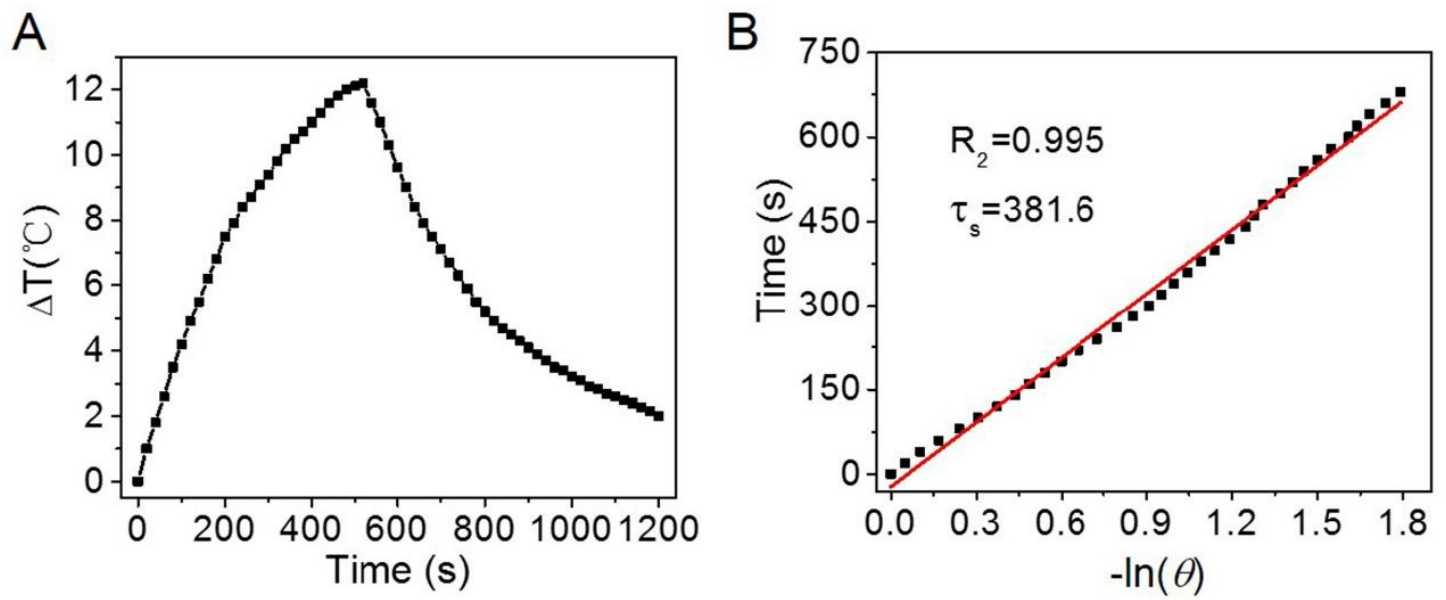

Figure S10. A) Heating/Cooling experiment of PPOSD aqueous solution (50 $\mu \mathrm{g} / \mathrm{mL})$ under $1.0 \mathrm{~W} / \mathrm{cm}^{2} 808 \mathrm{~nm}$ laser irradiation. B) The cooling time verses $-\ln (\theta)$. 

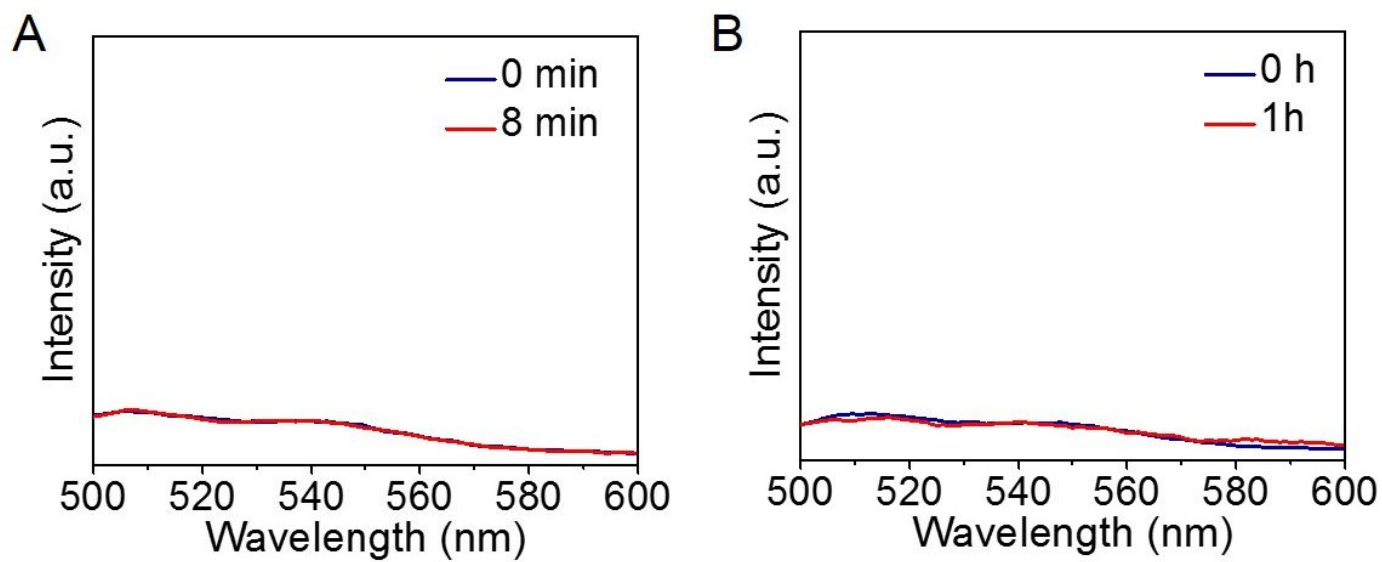

Figure S11. Fluorescence spectra changes of PPOSD solution $(50 \mu \mathrm{g} / \mathrm{mL})$ together with $\mathrm{CO}$ probe and $\left.\mathrm{PdCl}_{2} \mathrm{~A}\right)$ before and after $808 \mathrm{~nm}$ laser irradiation $\left(1 \mathrm{~W} / \mathrm{cm}^{2}, 8\right.$ min); B) under $60^{\circ} \mathrm{C}$ in dark for $1 \mathrm{~h}$. 


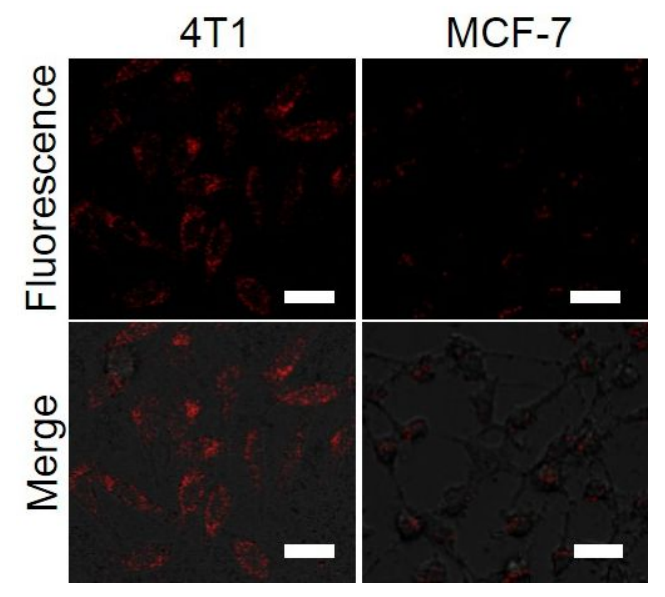

Figure S12. CLSM pictures of 4T1 and MCF-7 cells co-incubated with PPOSD (50 $\mu \mathrm{g} / \mathrm{mL}$ ) for $4 \mathrm{~h}$. The scale bar was $10 \mu \mathrm{m}$. Ex: $488 \mathrm{~nm}$; Em: 500-550 nm. 


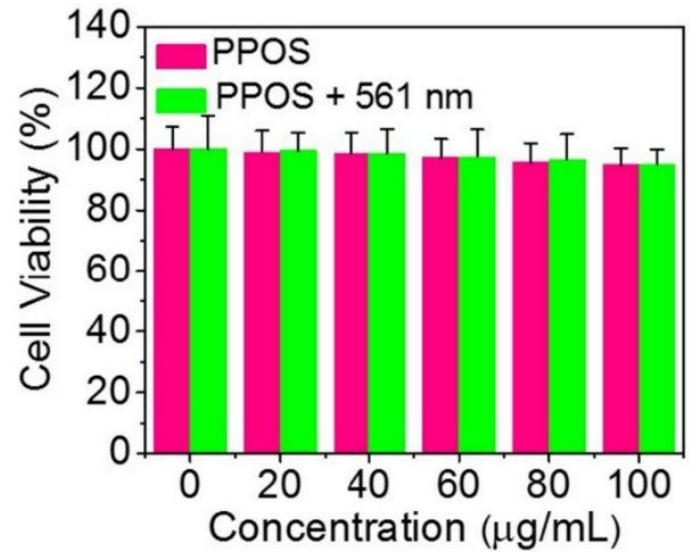

Figure S13. Cell viability of 4T1 cells treated with PPOS, $561 \mathrm{~nm}$ laser and PPOS + $561 \mathrm{~nm}$ laser irradiation $\left(0.5 \mathrm{~W} / \mathrm{cm}^{2}, 10 \mathrm{~min}\right)$. 


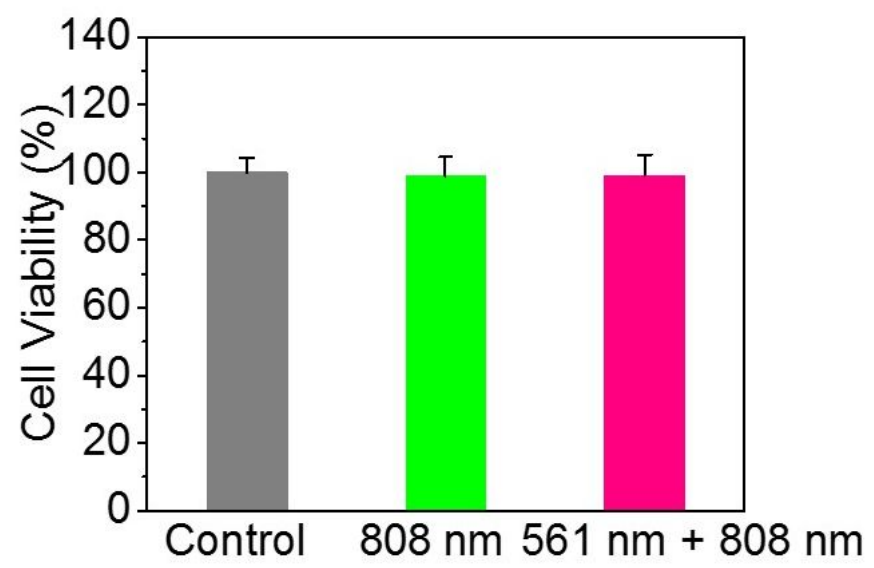

Figure S14. Cell viability of 4T1 cells treated with $808 \mathrm{~nm}$ and $561 \mathrm{~nm}+808 \mathrm{~nm}$ laser irradiation (561 nm laser: $0.5 \mathrm{~W} / \mathrm{cm}^{2}, 10 \mathrm{~min}$; $808 \mathrm{~nm}$ laser: $1 \mathrm{~W} / \mathrm{cm}^{2}, 10 \mathrm{~min}$ ). 

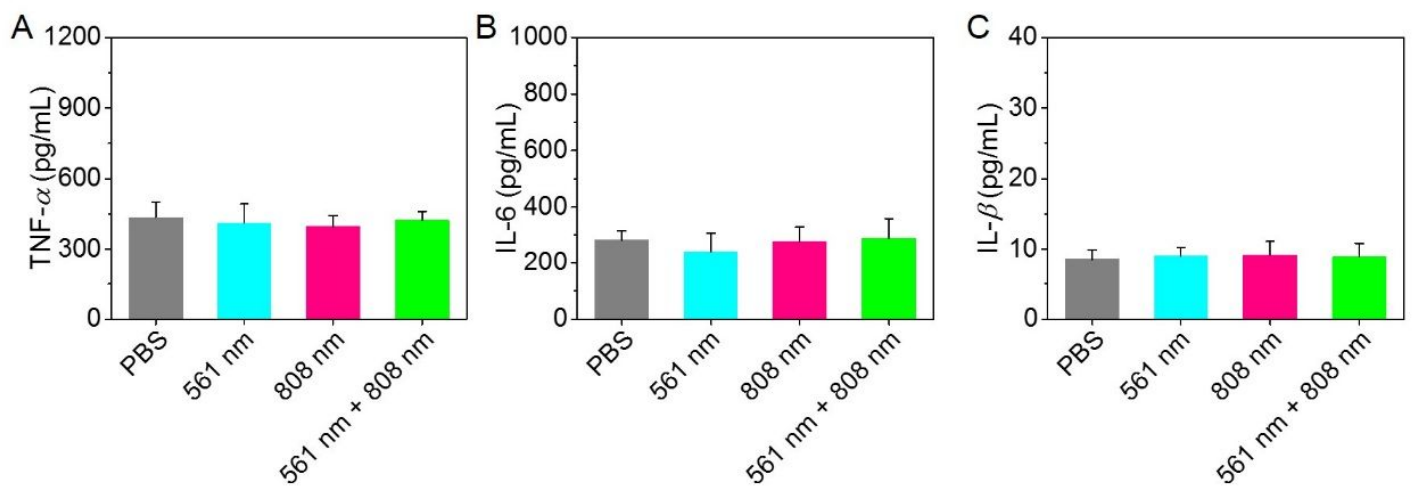

Figure S15. A) TNF- $\alpha$, B) IL-6, and C) IL-1 $\beta$ levels of RAW 264.7 macrophages after treatment with media of different $4 \mathrm{~T} 1$ cell samples. 4T1 cells were irradiated with $561 \mathrm{~nm}\left(0.5 \mathrm{~W} / \mathrm{cm}^{2}, 10 \mathrm{~min}\right)$ and $/$ or $808 \mathrm{~nm}\left(1 \mathrm{~W} / \mathrm{cm}^{2}, 10 \mathrm{~min}\right)$ laser, $\mathrm{n}=3$. 


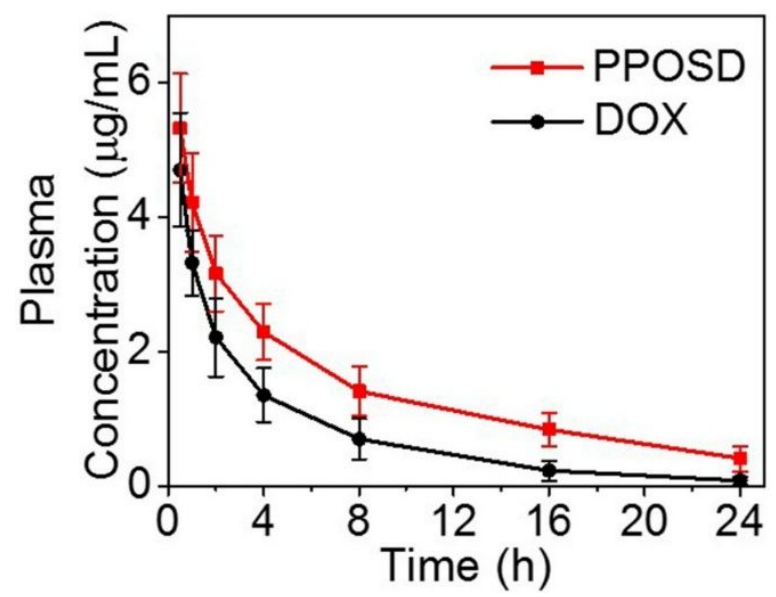

Figure S16. Pharmacokinetic profiles of PPOSD and free DOX after intravenous injection. 


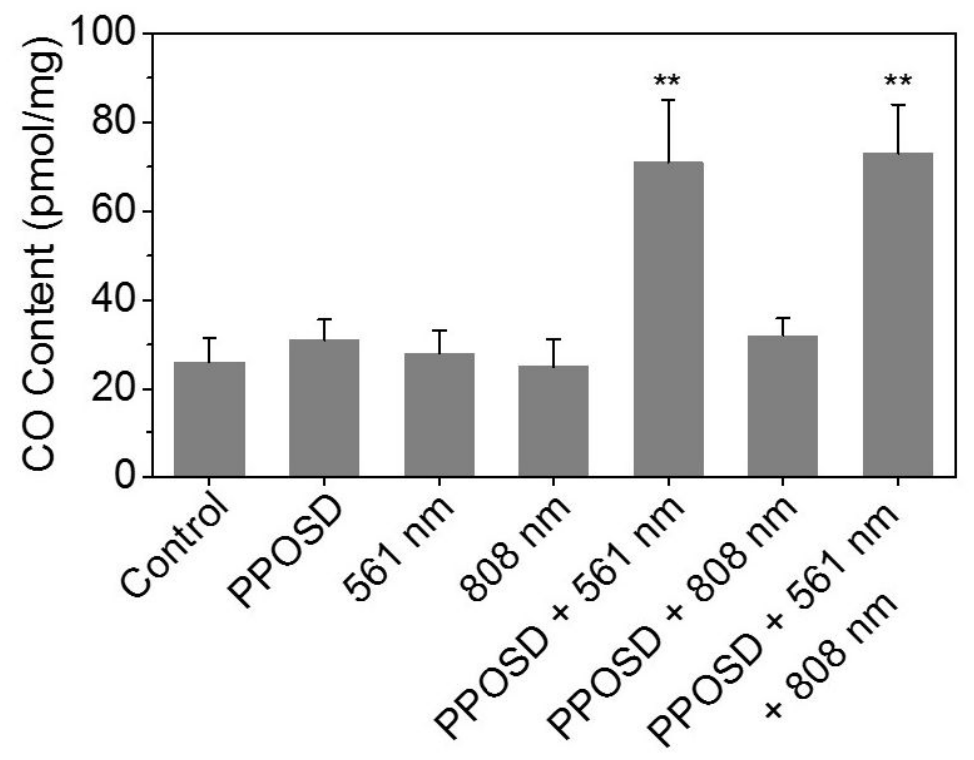

Figure S17. CO content in tumors after various treatments, $n=3 .{ }^{* *} \mathrm{p}<0.01$ compared to control group. 


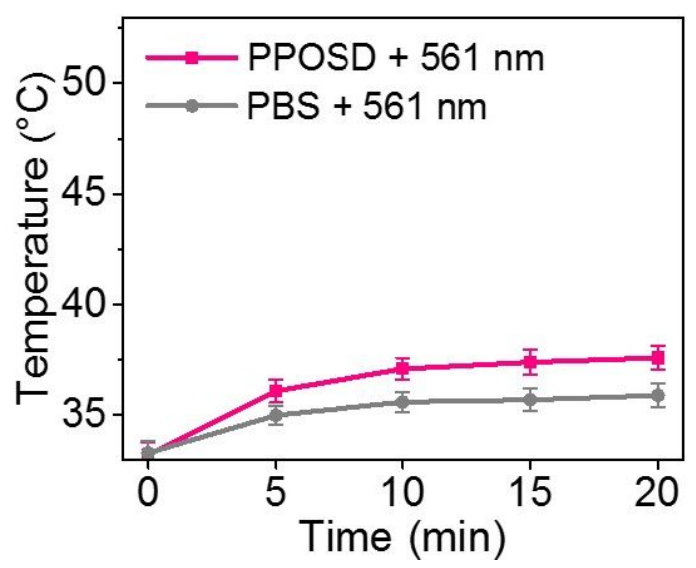

Figure S18. Temperature increase curves of $4 \mathrm{~T} 1$ tumors after the injection of PBS and PPOSD upon $561 \mathrm{~nm}$ laser irradiation $\left(0.5 \mathrm{~W} / \mathrm{cm}^{2}\right)$. 

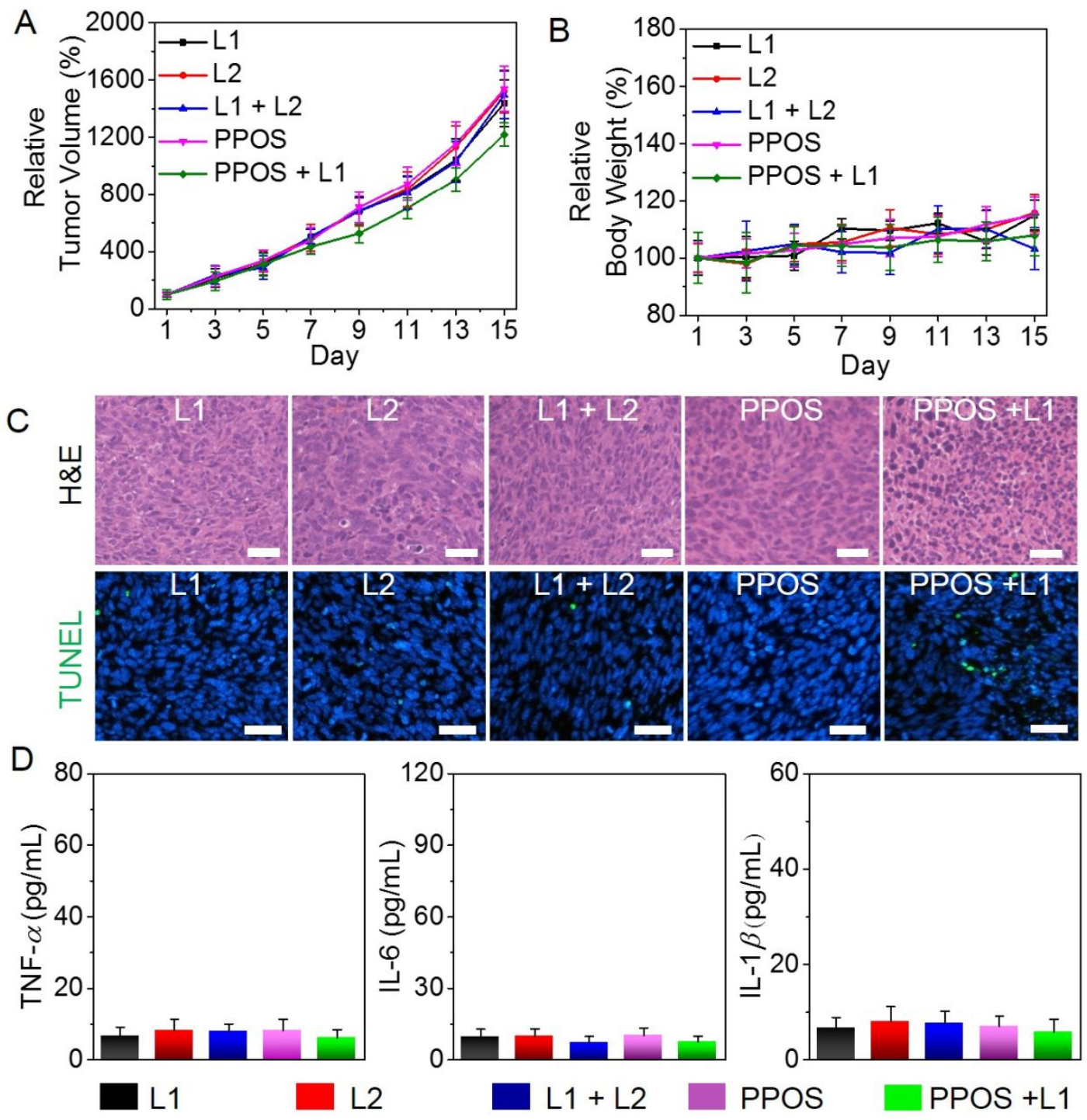

Figure S19. A) Relative tumor volume and B) body weight curves of PPOS and PPOS + $561 \mathrm{~nm}$ laser irradiation groups; C) H\&E and TUNEL staining results of tumors from different groups of mice at $24 \mathrm{~h}$ after the treatments. The scale bar was $50 \mu \mathrm{m} . \mathrm{D})$ Cytokine levels of TNF- $\alpha$, IL-6, and IL- $1 \beta$ in sera of mice from different groups of mice at $24 \mathrm{~h}$ after the treatments, $\mathrm{n}=3 . \mathrm{L1}: 561 \mathrm{~nm}$ laser; L2: $808 \mathrm{~nm}$ laser. 


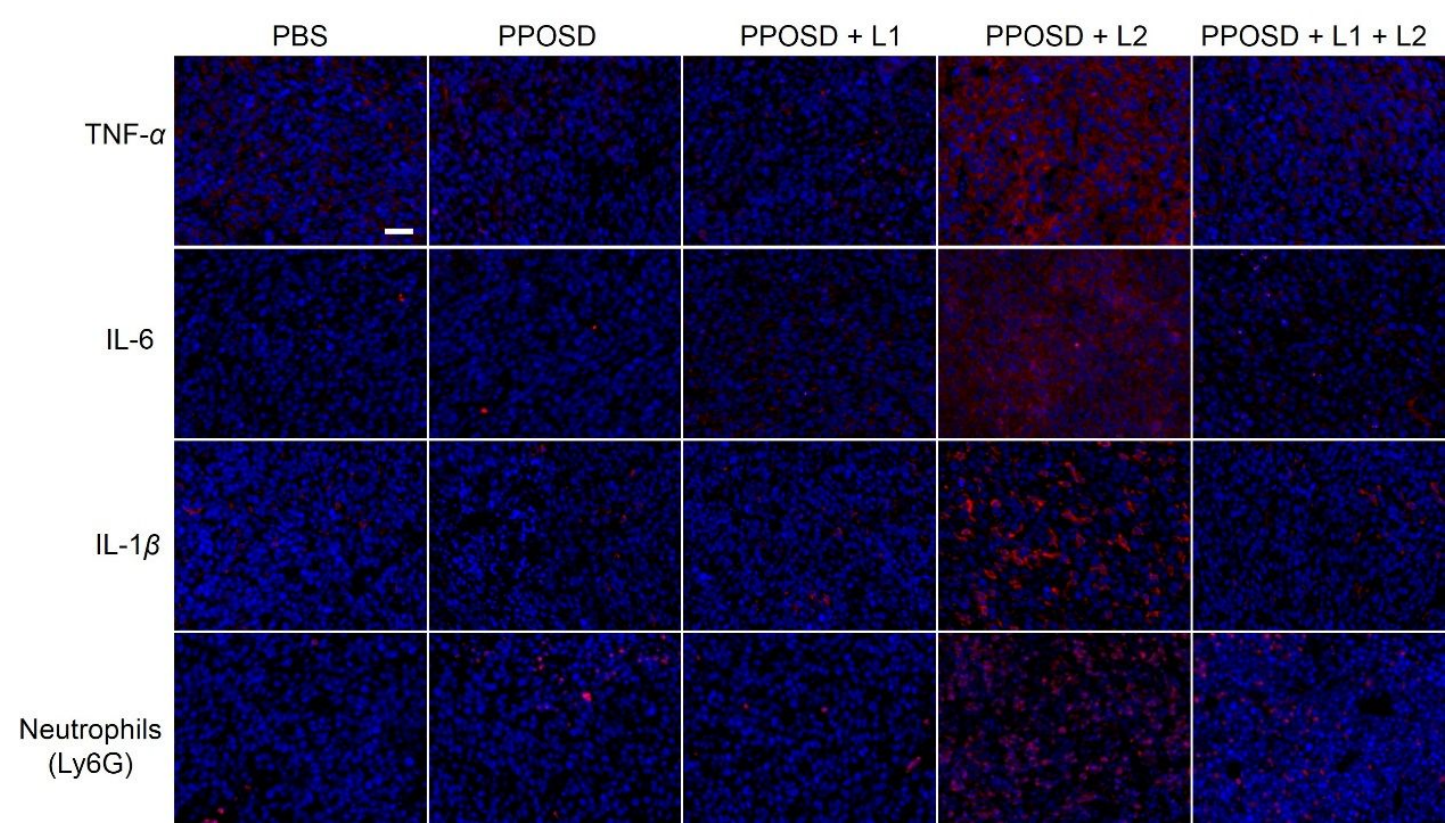

Figure S20. A) Representative immunostaining for TNF- $\alpha$, IL-6, IL- $1 \beta$, and lymphocyte antigen 6G (Ly6G, a marker for neutrophils) in tumor tissues from mice after various treatments. L1: $561 \mathrm{~nm}$ laser; L2: $808 \mathrm{~nm}$ laser. All pictures share the same scale bar of $50 \mu \mathrm{m}$. 


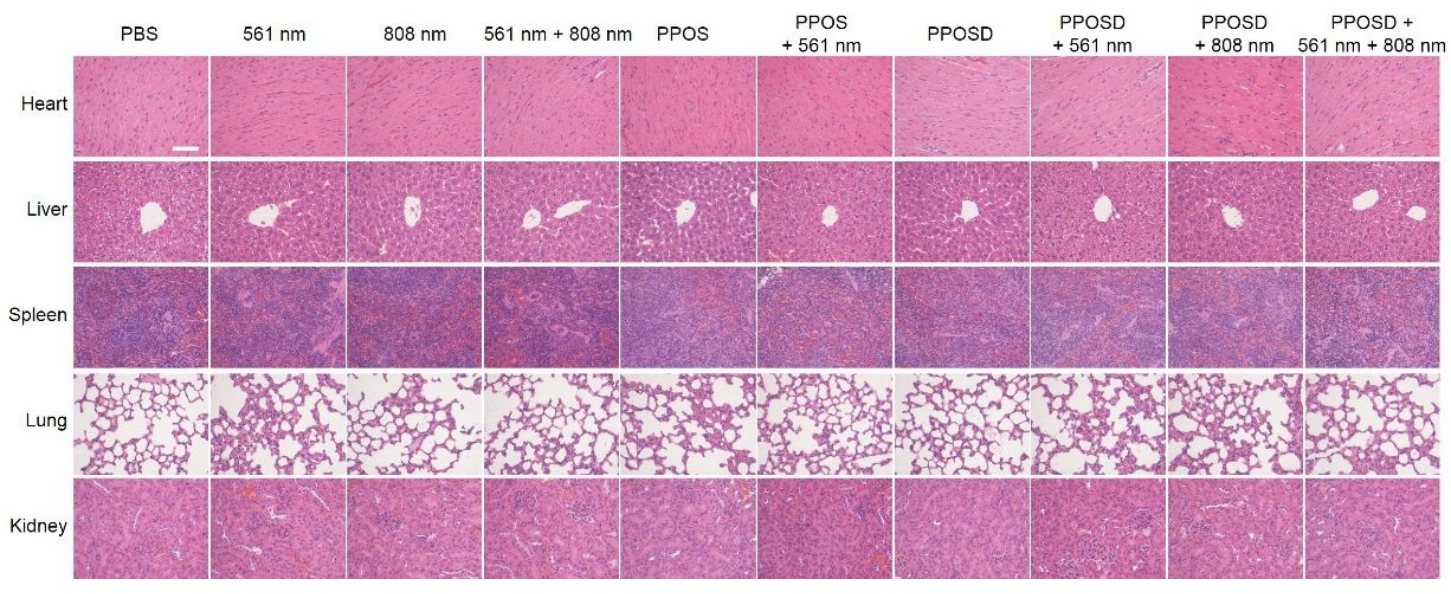

Figure S21. H\&E staining of major organs from mice in different groups on the 15 th day. All pictures share the same scale bar of $50 \mu \mathrm{m}$. 


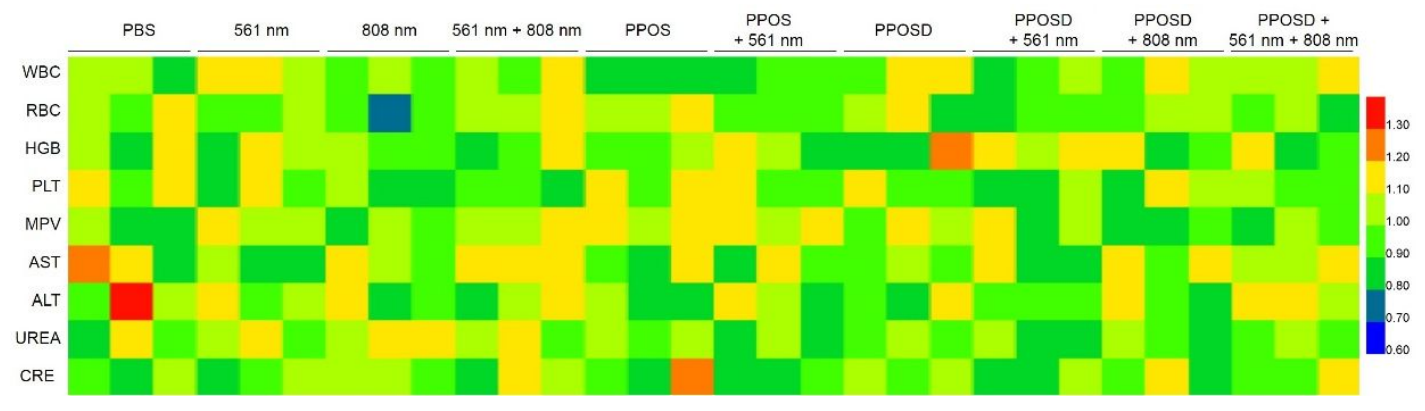

Figure S22. Blood biochemistry examination results of various groups on the 15 th day. 